\title{
Ranging behaviour of juvenile red foxes and its implications for management
}

\author{
Charles P. J. ROBERTSON, Philip J. BAKER* and Stephen HARRIS
}

Robertson C. P. J., Baker P. J. and Harris S. 2000. Ranging behaviour of juvenile red foxes and its implications for management. Acta Theriologica 45: 525-535.

The diurnal and nocturnal movement patterns of juvenile foxes Vulpes vulpes (Linneaus, 1758) were investigated in Bristol, UK. Juvenile and adult foxes were radio-tracked between May and December in three consecutive years. In the months preceding the main dispersal period (May-September), cubs showed a gradual increase in the area over which they ranged, and this was reflected both in the use of diurnal lying-up sites and nocturnal patterns of movement. However, their behaviour was highly focused at secure den sites and rendezvous sites. There was no significant difference in the movement patterns of male and female cubs. By the end of August, the nocturnal movement patterns of cubs were comparable with resident adult animals with the exception of their average speed of travel. During the onset of the main dispersal period (October-December) subadults showed the same movement patterns as adults. These results are discussed within the context of fox management by the distribution of baits. It is proposed that the low bait uptake rate of juveniles is associated with their limited ranging behaviour as cubs, and with differences in patterns of range utilisation as subadults.

School of Biological Sciences, University of Bristol, Woodland Road, Bristol BS8 1UG, UK, e-mail: P.J.Baker@bristol.ac.uk

Key words: Vulpes vulpes, cub, movement, radio-tracking

\section{Introduction}

Management of canids may be undertaken for several reasons: limiting predation on species of agricultural, sporting and conservation interest (eg Harris and Saunders 1993, Saunders et al. 1995, Reynolds and Tapper 1996), the control of disease (Macdonald and Voigt 1985, Harris et al. 1992) and for their own conservation (Ginsberg and Macdonald 1990). In Europe, the red fox Vulpes vulpes (Linneaus, 1758) is the principal vector of rabies (Harris et al. 1992) and, although currently clear of rabies, the introduction of the disease into the United Kingdom poses particular management problems because of the prevalence of high-density populations of foxes in many British cities (Harris and Rayner 1986). Currently the preferred form of control is via the distribution of poisoned baits (Harris et al. 1992). The successful distribution and uptake of these baits will be dependent upon

\footnotetext{
* Corresponding author
} 
patterns of range and habitat use by the target population (eg Doncaster and Macdonald 1997, Saunders et al. 1997). However, in one trial the uptake rate of these baits was far below that required for effective control, particularly for juveniles (Trewhella et al. 1991).

Despite extensive research on the patterns of movement of adult animals (White et al. 1996, Doncaster and Macdonald 1997), relatively little attention has been paid to juvenile foxes (but see Woollard and Harris 1990), despite the fact that for much of the year these are the most abundant age class. Furthermore, juveniles are more likely to make dispersal movements than adults (Harris and Trewhella 1988) and consequently they are more likely to spread diseases such as rabies. In this paper, we describe the diurnal and nocturnal patterns of movement of juvenile foxes in Bristol, UK from the age of approximately 8 weeks to 8 months. Throughout we compare the movement patterns of the juveniles to those of adults from the same social groups. Patterns of interaction between adults and cubs before the attainment of nutritional independence have already been described (Baker et al. 1998).

\section{Material and methods}

The study was conducted in north-west Bristol between 1991 and 1993 . The study site occupied an area of approximately $1.5 \mathrm{~km}^{2}$ and is characterised by semi-detached housing built during the inter-war years (Harris 1980). Other habitats present were playing fields, allotment gardens and a cemetery. In this paper, the term cub is used to denote animals $<6$ months old, subadult for animals aged 6-12 months, and adult refers to animals $>12$ months old (Harris and Trewhella 1988). Cubs and subadults are collectively referred to as juveniles. Dens denote secure locations, either above or below ground, where litters were born. Lying-up sites are specific points where individual foxes rest during the day, while rendezvous sites are general areas in which a number of cubs lie up reseatedly. Rendezvous sites generally contain both above- and below-ground lying-up sites in very close proximity. We have used an arbitrary separation distance of $100 \mathrm{~m}$ to cluster lying-up sites into rendezvous sites.

Between May and August 1991-1993, the pre-dispersal period (Harris and Trewhella 1988), the movement patterns of cubs from four contiguous groups were studied, with two groups studied in each year. Foxes were captured in box-traps placed in the gardens of cooperative householders. Additionally, some cubs were flushed from daytime rest sites and captured in nets (Harris 1980). All aninals were sexed, weighed and marked with plastic ear tags (Rototags, Dalton Supplies Ltd). Adults were aged by incisor wear (Harris 1978) and fitted with radio-collars transmitting at $173 \mathrm{MHz}$. Once cubs had reached a minimum weight of $1.8 \mathrm{~kg}$, expandable radio-collars were fitted as described by Robertson and Harris (1996). The birth date of litters was estimated from the physical characteristics of the cubs at their initial capture (sensu Sargeant et al. 1981).

Both cubs and adults were radio-tracked for a continuous eight-hour period between 20.00-04.00 GMT, with locations recorded every five minutes (Saunders et al. 1993, White et al. 1996). At each fix the animal was assigned to both a $25 \mathrm{~m}$ grid cell and to one of nine habitat categories (Sauncers et al. 1997) and classified as active or inactive. Only active fixes were used to determine range size and patterns of movement. Cubs were radio-tracked from July-August in 1991 and May-Augusi in 1992 and 1993. During 1992 adults and cubs were radio-tracked simultaneously. In addition to rocturnal patterns of movement, daytime lying up sites were recorded every day in 1992 and approximately twice weekly in 1991 and 1993.

During November and December 1993, the onset of the main dispersal period (Harris and Trewhella 1988), adult and subadult animals from two groups were radio-tracked intensively, with 
each individual being followed for up to five consecutive nights. All of the subadults had previously been tracked as cubs and all subsequently remained on their natal group as adults.

Juvenile movement parameters were compared with those of adult animals resident on the same territory. Adult home ranges were used to delimit the size and configuration of group territories and hence describe the total area available to the juveniles. Adult home ranges were delimited by minimum convex polygons (MCPs) as these accurately reflect patterns of space use in this population (Saunders et al. 1993). A minimum of 200 active fixes was required to obtain an asymptotic home range estimate and was calculated from data pooled over several nights (Harris et al. 1990).

Home range estimates for juveniles could not be calculated in the same way as for adults, as the area over which juveniles ranged increased progressively during their development. To describe this change in ranging behaviour, movement parameters derived from radio-tracking data were analysed on a single night basis. The following parameters were calculated for each night's radio-tracking: nightly range area (MCP), range length (maximum diameter), total distance travelled, average speed of travel and percentage time spent active. The kernel method (Worton 1980) was used to determine internal patterns of range utilisation. For each group, the optimal kernel smoothing parameter (Wray et al. 1992) was determined for the adults' tracking data and applied to that for the juveniles. Contours were plotted at $10 \%$ increments of the maximum matrix value. Measures of the speed of movement were calculated only where the separation distance for successive locations was greater than zero.

Radio-tracking data from each litter in each year were pooled by month. Individual cubs were tracked up to three times in any given month. However, due to differences in collar retention time (Robertson and Harris 1996), data for individual cubs were not spread evenly across all months. To avoid any biases, only a single night's data were used for each cub in each month: replicate nights were removed at random. The nightly ranging behaviour of adult foxes did not differ between males or females or between dominant and subordinate individuals resident on the same group (Baker 1995). Consequently, each night's data from all adults radio-tracked were pooled for analysis. All statistical tests were carried out using SPSS ${ }^{\circledast}$ (Norušis 1990). Parametric statistics were used unless the data were found not to be normally distributed or covariant.

\section{Results}

Four different social groups were studied (Table 1), one group for all three years and three for one year only. These groups contained 44 cubs. Group size ranged from 3 to 6 adults. Based upon physical characteristics, all litters were estimated to have been born within one week of each other and radio-tracking data have therefore been pooled by chronological month. In total, 33 cubs were radio-tracked for a total of 94 nights; 75 nights' data were utilised for statistical analyses.

\section{Diurnal movement during the pre-dispersal period}

The changing pattern of use of diurnal lying-up sites is summarised in Table 2 and illustrated in Fig. 1. In total, diurnal lying-up sites were recorded for 609 cub-days. In May, cubs were still lying-up at their natal dens. Of the four groups studied in May, two utilised two den sites and two used only one; four of these dens were under sheds and two in earths. From June onwards, progressively more lying-up sites were used. However, many of these locations were in adjacent $25 \mathrm{~m}$ grid cells (Fig. 1). When each cluster of lying-up sites was grouped as discrete rendezvous sites, the number of these also increased between May and August.

Each cub used more lying-up sites as the summer progressed and so with time the cubs became more scattered and fewer lay up in groups. Where natal dens had 
Table 1. Summary of the radio-tracking data collected on the ranging behaviour of juvenile red foxes. Figures in parentheses indicate the number of nights' data used in statistical analyses.

\begin{tabular}{|c|c|c|c|c|c|c|c|c|c|}
\hline \multirow[t]{2}{*}{ Year } & \multirow{2}{*}{$\begin{array}{l}\text { Social } \\
\text { group }\end{array}$} & \multirow{2}{*}{$\begin{array}{c}\text { Group } \\
\text { size }\end{array}$} & \multirow{2}{*}{$\begin{array}{c}\text { Min } \\
n \\
\text { cubs } \\
\text { present }\end{array}$} & \multicolumn{4}{|c|}{ Number of nights cubs radio-tracked during } & \multirow{2}{*}{$\begin{array}{c}n \\
\text { subadults } \\
\text { radio- } \\
\text { tracked }\end{array}$} & \multirow{2}{*}{$\begin{array}{c}n \\
\text { adults } \\
\text { radio- } \\
\text { tracked }\end{array}$} \\
\hline & & & & May & June & July & August & & \\
\hline \multirow{2}{*}{1991} & ey Croft & 3 & 5 & - & - & $2(2)$ & $4 \quad(2)$ & - & $2(12)$ \\
\hline & er Abbey Road & 5 & 5 & - & - & $4 \quad(3)$ & $4 \quad(3)$ & - & $2(7)$ \\
\hline \multirow{2}{*}{1992} & ey Croft & 6 & 8 & 3 (3) & $5 \quad(3)$ & $4 \quad(2)$ & 2 (1) & - & $2(8)$ \\
\hline & dyleaze & 6 & 11 & 7 (5) & $6(5)$ & 9 (7) & $6 \quad(5)$ & - & 1 (18) \\
\hline \multirow{2}{*}{\multicolumn{2}{|c|}{$\begin{array}{l}1993 \text { Barley Croft } \\
\text { Briarwood }\end{array}$}} & 4 & 11 & $2(2)$ & 7 (7) & $8(7)$ & $6 \quad(6)$ & $3(10)$ & $1 \quad(5)$ \\
\hline & & 3 & 4 & $4 \quad(2)$ & $5 \quad(4)$ & $3 \quad(3)$ & 3 (3) & $1 \quad(4)$ & 1 (4) \\
\hline Total & & & & $16(12)$ & 23 (19) & $30(24)$ & $25(20)$ & $4(14)$ & $9(54)$ \\
\hline
\end{tabular}

Table 2. Summary of the changing pattern of the use of diurnal lie-up and rendezvous sites by juvenile red foxes in 1992. Figures indicate the total number of sites utilised by the cubs radio-tracked in that month; figures in parentheses indicate the range for individual cubs within that month.

\begin{tabular}{|c|c|c|c|c|c|c|c|c|c|}
\hline \multirow{2}{*}{$\frac{\text { Social group }}{\text { Barley Croft }}$} & \multirow{2}{*}{$\begin{array}{l}\text { Number of } \\
\text { Cubs }\end{array}$} & \multicolumn{2}{|c|}{ May } & \multicolumn{2}{|c|}{ June } & \multicolumn{2}{|c|}{ July } & \multicolumn{2}{|c|}{ August } \\
\hline & & - & & 6 & & 2 & & 2 & \\
\hline & Cub-days & - & & 90 & $(1-29)$ & 30 & $(4-26)$ & 33 & $(16-17)$ \\
\hline & Lie-up sites & - & & 5 & $(2-4)$ & 8 & $(3-7)$ & 9 & $(5-7)$ \\
\hline & Rendezvous sites & - & & 4 & $(1-4)$ & 5 & $(3-4)$ & 5 & $(2-4)$ \\
\hline \multirow[t]{4}{*}{ Sandyleaze } & Cubs & 6 & & 9 & & 7 & & 6 & \\
\hline & Cub-days & 52 & $(1-17)$ & 147 & $(3-30)$ & 161 & $(15-30)$ & 96 & $(2-30)$ \\
\hline & Lie-up sites & 4 & $(1-3)$ & 11 & $(1-9)$ & 25 & $(2-12)$ & 24 & $(1-11)$ \\
\hline & Rendezvous sites & 3 & $(1-3)$ & 5 & $(1-5)$ & 6 & $(2-6)$ & 6 & $(1-6)$ \\
\hline
\end{tabular}

nearby vegetation cover, these continued to be used as rendezvous sites throughout the summer. In July and August security was apparently a key factor in the selection of lying-up sites, which were often in dense vegetation at or close to rendezvous sites.

\section{Patterns of nocturnal movement during the pre-dispersal period}

The data for each ranging parameter for the cubs were averaged for each sex in each social group in each month, and the sexes compared. There were no differences between the sexes for any of the five parameters (Wilcoxon matched-pairs test: $n=13$ group months in all cases, $z_{(\mathrm{MCP} \text { area })}=-0.91 ; z_{(\mathrm{MCP} \text { length })}=-0.03$; $z_{\text {(distance travelled) }}=-0.38 ; z_{\text {(average speed) }}=-0.07 ; z_{\text {(activity) }}=-0.66 ; p>0.05$ in all 
A
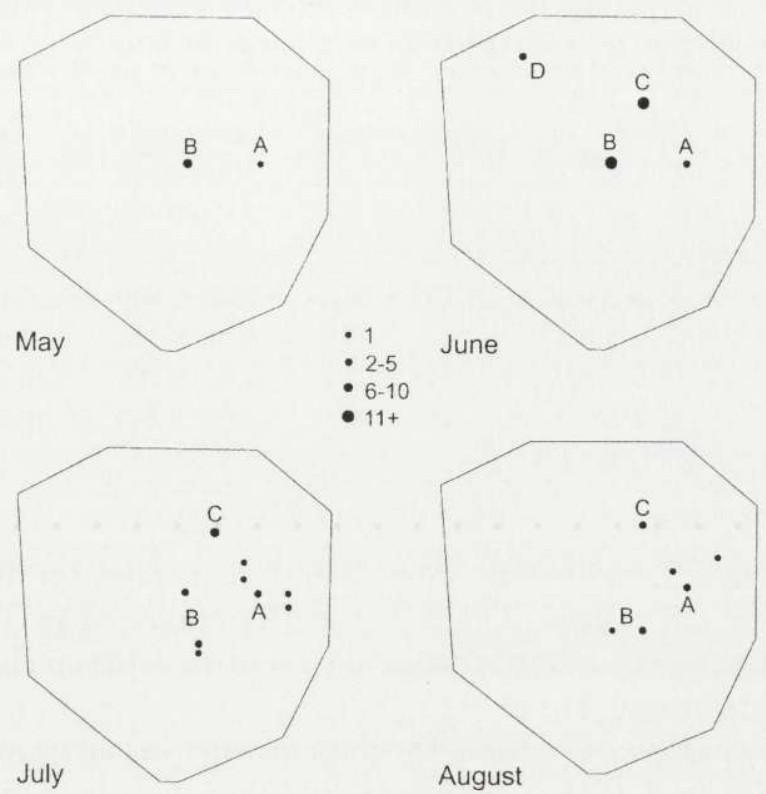

- $2-5$

$11+$

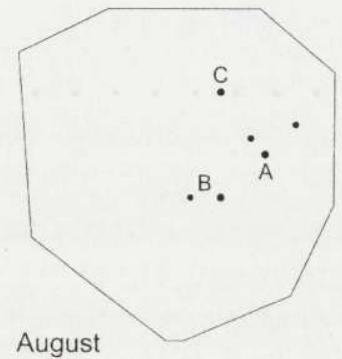

B
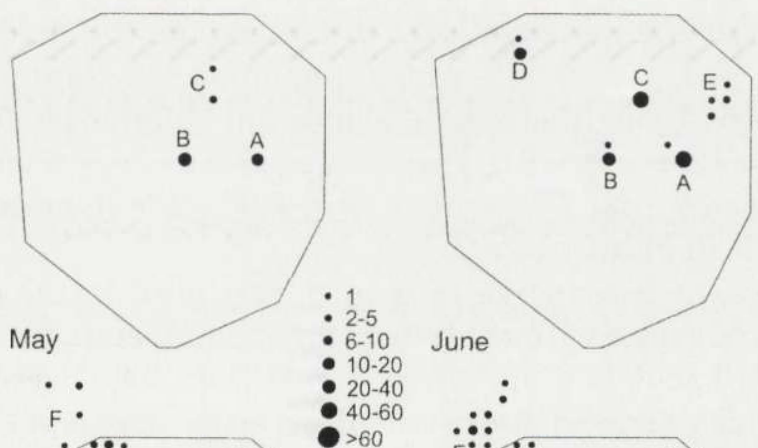

June
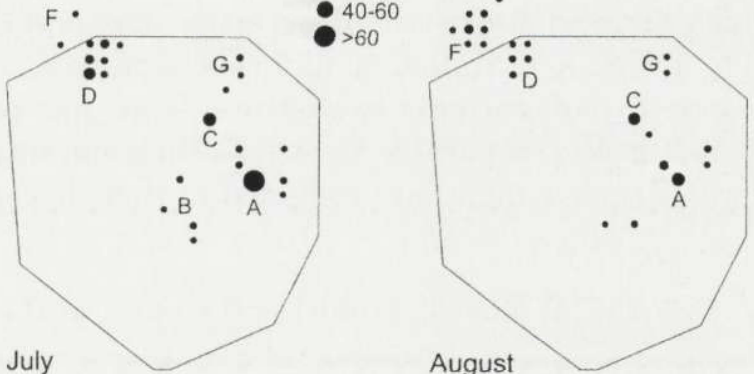

Fig. 1. Diurnal lying up sites of a single cub (A) and the whole litter of cubs (B) on the Sandyleaze range in 1992. The minimum convex polygon is the home range for an adult female ( $n=18$ nights). The letters denote the principal lying-up sites used by the cubs, the alphabetical order corresponding to the chronological sequence in which they were used. Sample sizes were: (A) 7 positions in May, 27 in June, 17 in July, 14 in August; (B) 52 in May, 147 in June, 161 in July, and 96 positions in August. 
Table 3. Nightly movement parameters (mean \pm SE) for red fox cubs in May, June, July, and August. Figures are based on data from one night for each cub per month.

\begin{tabular}{|c|c|c|c|c|c|c|}
\hline Month & $n$ & $\begin{array}{l}\text { MCP area } \\
\text { (ha) }\end{array}$ & $\begin{array}{l}\text { MCP length } \\
\text { (m) }\end{array}$ & $\begin{array}{c}\text { Distance } \\
\text { travelled } \\
(\mathrm{m})\end{array}$ & $\begin{array}{c}\text { Average } \\
\text { speed } \\
(\mathrm{m} / \mathrm{min})\end{array}$ & $\begin{array}{c}\text { Activity } \\
(\%)\end{array}$ \\
\hline May & 12 & $1.3 \pm 0.5$ & $157 \pm 30$ & $1326 \pm 259$ & $7.9 \pm 0.9$ & $81 \pm 3$ \\
\hline June & 19 & $2.0 \pm 0.4$ & $215 \pm 20$ & $2040 \pm 168$ & $9.0 \pm 0.4$ & $78 \pm 3$ \\
\hline July & 24 & $5.6 \pm 0.9$ & $342 \pm 35$ & $3033 \pm 290$ & $10.7 \pm 0.7$ & $84 \pm 2$ \\
\hline August & 20 & $8.9 \pm 1.3$ & $434 \pm 36$ & $3605 \pm 242$ & $12.0 \pm 0.5$ & $83 \pm 3$ \\
\hline
\end{tabular}

cases). Male and female data were therefore pooled for further analyses. The parameters for cub ranging behaviour are summarised in Table 3. The changing pattern of range use by a single cub and the entire litter on the Sandyleaze group in 1992 are illustrated in Fig. 2.

To test for changes with time, the data for each social group in each month were averaged, and the averages compared between months using a Friedman's test. Data from 1991, when no radio-tracking was carried out in May or June, were excluded. There was no significant difference for the percentage of time active $\left(\chi^{2}=3.2, \mathrm{df}=3, p>0.05\right)$, which remained constant at about $80 \%$ of the eight-hour period, but there were significant differences for all other variables $\left(\chi_{(\mathrm{MCP} \text { area })}^{2}=12.0, p<0.01 ; \chi^{2}\right.$ (MCP length) $=11.1, p<0.05 ; \chi^{2}$ (distance travelled) $=$ $11.1, p<0.05 ; \chi^{2}$ (average speed) $=11.1, p<0.05 ; \mathrm{df}=3$, mean rank May $<$ June $<$ July $<$ August in all cases).

Cub movement parameters in August, just prior to the onset of the dispersal period, were compared with adult movement parameters for four groups (Table 4); groups which had less than three nights' cub data were excluded. The only parameter which showed consistent differences across all four groups was the average speed of movement. Statistical differences between nightly range area and range length were evident for only two groups. Thus just prior to dispersal, cubs were moving over areas comparable in size to their parents, but their continued cautious exploratory movements are reflected in their lower speed of travel.

\section{Patterns of nocturnal movement during the onset of the dispersal period}

Radio-tracking data for adult and subadult animals were collected for two groups in 1993. There were no significant differences between adults and subadults in any of the parameters with the exception of the average speed of movement in the Briarwood group (Table 5). Thus, there were no apparent differences in the movement behaviour of adults and subadults during the onset of the dispersal period. 
A
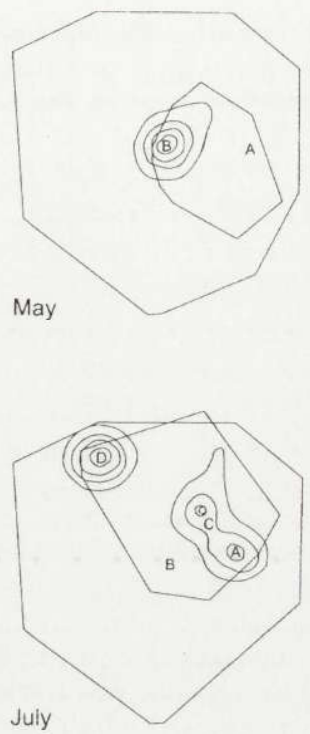

B
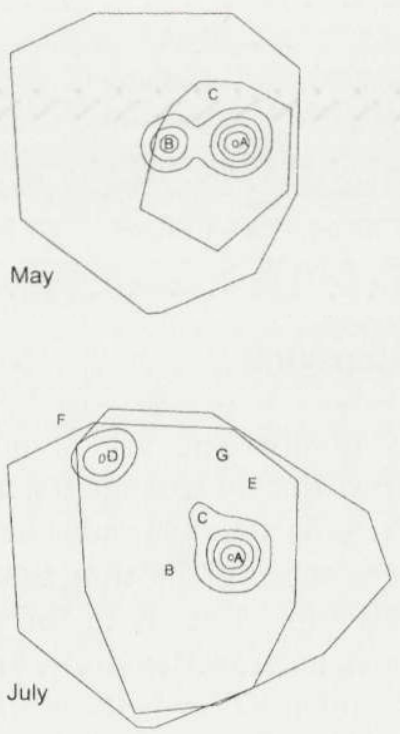
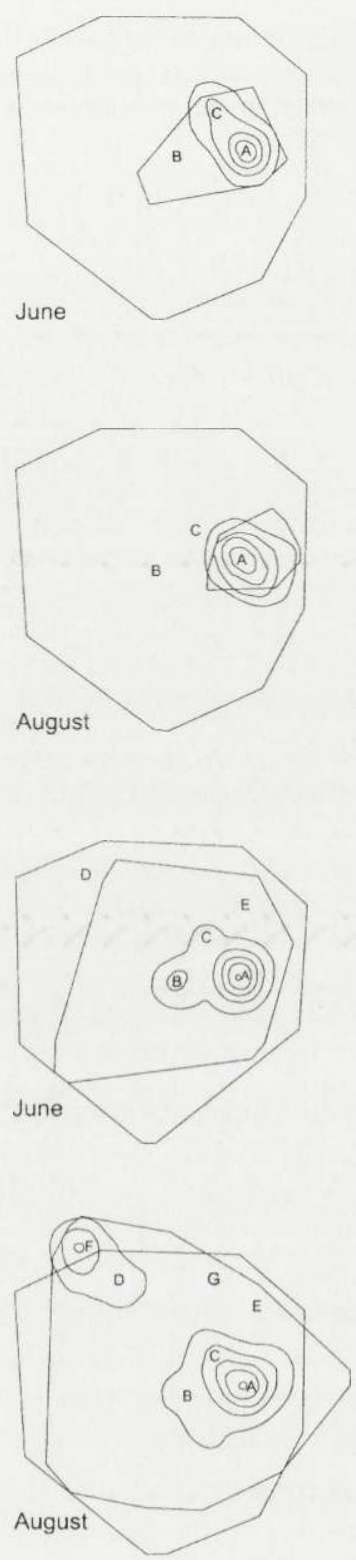

$500 \mathrm{~m}$

Fig. 2. Nocturnal range plots using the MCP and kernel methods to show the increase in ranging behaviour of a single cub (A) and the whole litter of cubs (B) on the Sandyleaze range in 1992. The outer minimum convex polygon is the home range for an adult female ( $n=18$ nights). The letters denote the principal lying-up sites used by the cubs as outlined in Fig. 1. For (A) only a single night's data from each month has been utilised. For (B) a single night's data from each cub were pooled: 5 cubs in May, 5 in June, 7 in July, and 5 in August. 
Table 4. Summary of two-tailed Mann-Whitney tests comparing the movement parameters of red fox cubs and adults in the same social group in August. ns $-p>0.05,{ }^{*}-p<0.05$ and ${ }^{* * *}-p<0.001 ; n_{\text {cub }}$ and $n_{\text {adult }}$ denote the number of nights radio-tracking data used in the samples of cub and adult movement, respectively.

\begin{tabular}{|c|c|c|c|c|c|c|c|c|c|c|c|c|c|}
\hline \multirow[t]{2}{*}{ Year } & \multirow[t]{2}{*}{ Social group } & \multirow{2}{*}{$n_{\text {cub }}$} & \multirow[t]{2}{*}{$n_{\text {adult }}$} & \multicolumn{2}{|c|}{$\begin{array}{l}\text { MCP } \\
\text { area }\end{array}$} & \multicolumn{2}{|c|}{$\begin{array}{c}\text { MCP } \\
\text { length }\end{array}$} & \multicolumn{2}{|c|}{$\begin{array}{l}\text { Distance } \\
\text { travelled }\end{array}$} & \multicolumn{2}{|c|}{$\begin{array}{l}\text { Average } \\
\text { speed }\end{array}$} & \multicolumn{2}{|c|}{ Activity } \\
\hline & & & & $z$ & $p$ & $z$ & $p$ & $z$ & $p$ & $z$ & $p$ & $z$ & $p$ \\
\hline 1991 & Lower Abbey Road & 3 & 7 & -2.32 & * & -1.55 & ns & -2.32 & $*$ & -2.31 & $*$ & -2.32 & * \\
\hline 1992 & Sandyleaze & 5 & 18 & -1.53 & ns & -0.67 & ns & -1.57 & ns & -3.28 & $* * *$ & -0.07 & ns \\
\hline \multirow[t]{2}{*}{1993} & Barley Croft & 6 & 5 & -0.91 & ns & -0.18 & $\mathrm{~ns}$ & -0.73 & ns & -2.74 & * & -2.47 & $*$ \\
\hline & Briarwood & 3 & 4 & -2.12 & $*$ & -2.12 & $*$ & 0.00 & ns & -2.14 & * & -1.06 & $\mathrm{~ns}$ \\
\hline
\end{tabular}

Table 5. Summary of statistical comparisons of the movement parameters of subadult and adult red foxes in November 1993. Three subadult males were radio-tracked in the Barley Croft group and one in the Briarwood group. $n$ denotes the number of nights each animal was tracked. Data from the Barley Croft group were analysed using the Kruskal-Wallis test. Data from the Briarwood group were analysed using the Mann-Whitney test. All tests are two-tailed: ns denotes $p>0.05 ; n_{\text {sad }}$ and $n_{\text {ad }}$ denote the number of nights radio-tracking data used in the samples of subadult and adult movement, respectively.

\begin{tabular}{|c|c|c|c|c|c|c|c|}
\hline Social group & $n_{\text {sad }}$ & $n_{\text {ad }}$ & $\begin{array}{l}\text { MCP } \\
\text { area }\end{array}$ & $\begin{array}{c}\text { MCP } \\
\text { length }\end{array}$ & $\begin{array}{l}\text { Distance } \\
\text { travelled }\end{array}$ & $\begin{array}{l}\text { Average } \\
\text { speed }\end{array}$ & Activity \\
\hline Barley Croft & $4,4,2$ & 5 & $\chi^{2}=5.17, \mathrm{~ns}$ & $\chi^{2}=5.89, \mathrm{~ns}$ & $\chi^{2}=6.77, \mathrm{~ns}$ & $\chi^{2}=4.14, \mathrm{~ns}$ & $\chi^{2}=6.77, \mathrm{~ns}$ \\
\hline Briarwood & 4 & 4 & $z=0.19, \mathrm{~ns}$ & $z=0.75, \mathrm{~ns}$ & $z=0.08, \mathrm{~ns}$ & $z=5.33, p<0.05$ & $z=1.71, \mathrm{~ns}$ \\
\hline
\end{tabular}

\section{Discussion}

Baiting campaigns, whether they involve the use of poisons, vaccines for controlling diseases such as rabies, or fertility control agents, are believed to be the most effective means of managing fox populations (Saunders et al. 1995). However, few studies have evaluated the effectiveness of baiting campaigns in reaching different age and sex classes of a population. A study in the city of Bristol found that 2.1 times as many adults as cubs took baits in May/June, and 1.2 times as many adults as subadults in November/December (Trewhella et al. 1991). This study suggests that the difficulty in reaching juvenile foxes in baiting campaigns is likely to be due to their reduced ranging behaviour and the concentration of their activity at secure sites, behaviour which appears to be typical of the canids. Studies on wolves Canis lupus (van Ballenberghe et al. 1975), red foxes (Storm et al. 1976), arctic foxes Alopex lagopus (Eberhardt et al. 1983) and coyotes Canis latrans (Harrison et al. 1991) all found that cubs were initially reared at secure underground sites, the litter sometimes being split between two or more such dens, and that early movements were concentrated around these sites. 
In wolves and coyotes, den sites were subsequently abandoned in favour of secure rendezvous sites which acted as social foci for the whole group (Joslin 1967). This is true also of the foxes in the Bristol population (Baker 1995). The post-denning behaviour of juvenile red foxes has not previously been described in detail, but this study found that their behaviour is very similar to that described for wolves by Joslin (1967). Most of the nightly activity occurred at rendezvous sites, which had extensive vegetation cover and were comparatively undisturbed compared to the rest of the range. Rendezvous sites selected by other canids also comprised areas with dense vegetation cover that provided a visually cluttered environment with enhanced security (van Ballenberghe et al. 1975, Harrison et al. 1991). Thus rendezvous sites used by red foxes appear to be very similar both in structure and function to those reported for other species of canids, and their use for rearing cubs would appear to be widespread within the family.

Rendezvous sites continued to be the main foci for activity right through August. Use of these sites confers multiple benefits. Besides being secure, they were areas where cubs could learn to forage for themselves, and because all the cubs in the group were using the same few rendezvous sites and they were frequently visited by adult members of the group, they acted as important social foci. During the period prior to the attainment of nutritional independence, most social interactions between cubs and adults occurred at these rendezvous sites, as did a high proportion of those between adults (Baker 1995, Baker et al. 1998).

Between May and August, the nightly range sizes of cubs increased approximately seven-fold, and by August the nightly range area of cubs was similar to that of their parents, although they generally focused their activity at the same secure sites that they had used earlier in the season. In addition, their speed of movement was consistently lower than those of adults, and the pattern of behaviour appears to be one of cautious exploration while still concentrating their activity at secure sites. By the onset of the dispersal period (November-December), there were no differences in the movement parameters of philopatric subadults and adults. A previous study has shown that the movement behaviour of subadults in the intervening months (ie September-October) has also stabilised and is comparable with those of individuals subsequently resident in their natal group (Woollard and Harris 1990).

From a management perspective, these data imply that baiting campaigns implemented prior to the dispersal period risk missing cubs unless the rendezvous sites are included in the area where bait is distributed. Furthermore, bait may have to be concentrated at these sites in order that all the cubs are reached as, within litters, individual cubs may differ in their access to food resources. However, given that these sites are social foci, they may represent one means by which large numbers of animals could be targeted, thereby reducing the risk to non-target species and improving the efficacy of the baiting program. In this respect, the ability to distinguish characteristics of such sites would prove invaluable. Attempts to do this for two populations of foxes showed no obvious difference between breeding dens and other dens, although dens per se were preferentially distributed 
amongst certain habitat types (Meia and Weber 1992) and were characterised by certain physical properties (Uraguchi and Takahashi 1998).

Based on their movement behaviour, during the dispersal period juveniles should be as susceptible to baiting as adults. Woollard and Harris (1990) have also shown that during the dispersal period the movement patterns of subadult males that dispersed and those that did not are very similar in terms of home range area, core area size, speeds of movement and duration of activity. This was reflected in the study of Trewhella et al. (1991) who achieved similar bait uptake rates for adults and subadults. However, these rates (29\% and $23 \%$ respectively) were considerably lower than the $80 \%$ estimated as necessary to control a rabies outbreak (Smith and Harris 1991). Consequently, there is the need for further analysis of the movement behaviour of subadults with particular emphasis on the concordance or discordance of patterns of range use between animals within the same social group.

Acknowledgements: We thank the Royal Society for the Prevention of Cruelty to Animals (CPJR) for funding this study and the Science and Engineering Research Council (PJB) and the Dulverton Trust (SH) for financial support. S. Howell and L. Teagle made the radio transmitters.

\section{References}

Baker P. J. 1995. Factors affecting group formation in an urban fox (Vulpes vulpes) population. $\mathrm{Ph} \mathrm{D}$ thesis, University of Bristol, Bristol: 1-237.

Baker P. J., Robertson C. P. J., Funk S. M. and Harris S. 1998. Potential fitness benefits of group living in the red fox, Vulpes vulpes. Animal Behaviour 56: 1411-1424.

Doncaster C. P. and Macdonald D. W. 1997. Activity patterns and interactions of red foxes (Vulpes vulpes) in Oxford city. Journal of Zoology, London 241: 73-87.

Eberhardt L. E., Garrott R. A. and Hanson W. C. 1983. Den use by arctic foxes in northern Alaska. Journal of Mammalogy 64: 97-102.

Ginsberg J. R. and Macdonald D. W. 1990. Foxes, wolves, jackals, and dogs: an action plan for the conservation of canids. IUCN/SSC Canid specialist group, IUCN, Gland, Switzerland: 1-116.

Harris S. 1978. Age determination in the red fox (Vulpes vulpes) - an evaluation of technique efficiency as applied to a sample of suburban foxes. Journal of Zoology, London 184: 91-117.

Harris S. 1980. Home ranges and patterns of distribution of foxes (Vulpes vulpes) in an urban area, as revealed by radio tracking. [In: A handbook on biotelemetry and radio tracking. C. J. Amlaner and D. W. Macdonald, eds]. Pergamon Press, Oxford: 685-690.

Harris S., Cheeseman C. L., Smith G. C. and Trewhella W. J. 1992. Rabies contingency planning in Britain. [In: Wildlife rabies contingency planning in Australia. P. O'Brien and G. Berry, eds]. Bureau of Rural Resources, AGPS, Canberra, Proceedings No. 11: 63-77.

Harris S., Cresswell W. J., Forde P. G., Trewhella W. J., Woollard T. and Wray S. 1990. Home-range analysis using radio-tracking data - a review of the problems and techniques particularly as applied to the study of mammals. Mammal Review 20: 97-123.

Harris S. and Rayner J. M. V. 1986. A discriminant analysis of the current distribution of urban foxes (Vulpes vulpes) in Britain. Journal of Animal Ecology 55: 605-611.

Harris S. and Saunders G. 1993. The control of canid populations. Symposia of the Zoological Society of London 65: 441-464.

Harris S. and Trewhella W. J. 1988. An analysis of some of the factors affecting dispersal in an urban fox (Vulpes vulpes) population. Journal of Applied Ecology 25: 409-422. 
Harrison D. J., Harrison J. A. and O'Donaghue M. 1991. Predispersal movements of coyote (Canis latrans) pups in eastern Maine. Journal of Mammalogy 72: 756-763.

Joslin P. W. B. 1967. Movements and home sites of timber wolves in Algonquin Park. American Zoologist 7: 279-288.

Macdonald D. W. and Voigt D. R. 1985. The biological basis of rabies models. [In: Population dynamics of rabies in wildlife. P. J. Bacon, ed]. Academic Press, Oxford: 71-108.

Meia J.-S. and Weber J.-M. 1992. Characteristics and distribution of breeding dens of the red fox (Vulpes vulpes) in a mountainous habitat. Zeitschrift für Säugetierkunde 57: 137-143.

Norušis M. J. 1990. The SPSS guide to data analysis. SPSS Inc., Chicago: 1-470.

Reynolds J. C. and Tapper S. C. 1996. Control of mammalian predators in game management and conservation. Mammal Review 26: 127-156.

Robertson C. P. J. and Harris S. 1996. An expandable, detachable radio-collar for juvenile red foxes (Vulpes vulpes). Journal of Zoology, London 239: 382-387.

Sargeant A. B., Allen S. H. and Johnson D. H. 1981. Determination of age and whelping dates of live red fox pups. The Journal of Wildlife Management 45: 760-765.

Saunders G., Coman B., Kinnear J. and Braysher M. 1995. Managing vertebrate pests: foxes. Australian Government Publishing Service, Canberra: 1-141.

Saunders G., White P. C. L. and Harris S. 1997. Habitat utilisation by urban foxes (Vulpes vulpes) and the implications for rabies control. Mammalia 61: 497-510.

Saunders G., White P. C. L., Rayner J. M. V. and Harris S. 1993. Urban foxes (Vulpes vulpes): food acquisition, time and energy budgeting of a generalised predator. Symposia of the Zoological Society of London 65: 215-234.

Smith G. C. and Harris S. 1991. Rabies in urban foxes (Vulpes vulpes) in Britain: the use of a spatial stochastic model to examine the pattern of spread and evaluate the efficacy of different control régimes. Philosophical Transactions of the Royal Society of London B 334: 459-479.

Storm G. L., Andrews R. D., Phillips R. L., Bishop R. A., Siniff D. B. and Tester J. R. 1976. Morphology, reproduction, dispersal, and mortality of midwestern red fox populations. Wildlife Monographs 49: 1-82.

Trewhella W. J., Harris S., Smith G. C. and Nadian A. K. 1991. A field trial evaluating bait uptake by an urban fox (Vulpes vulpes) population. Journal of Applied Ecology 28: 454-466.

Uraguchi K. and Takahashi K. 1998. Den site selection and utilization by the red fox in Hokkaido, Japan. Mammal Study 23: 31-40.

Van Ballenberghe V., Erickson A. W. and Byman D. 1975. Ecology of the timber wolf in northeastern Minnesota. Wildlife Monographs 43: 1-43.

White P. C. L., Saunders G. and Harris S. 1996. Spatio-temporal patterns of home range use by foxes (Vulpes vulpes) in urban environments. Journal of Animal Ecology 65: 121-125.

Woollard T. and Harris S. 1990. A behavioural comparison of dispersing and non-dispersing foxes (Vulpes vulpes) and an evaluation of some dispersal hypotheses. Journal of Animal Ecology 59: 709-722.

Worton B. J. 1980. Kernel methods for estimating the utilization distribution in home-range studies. Ecology 70: 164-168.

Wray S., Cresswell W. J., White P. C. L. and Harris S. 1992. What, if anything, is a core area? An analysis of the problems of describing internal range configurations. [In: Wildlife telemetry: remote monitoring and tracking of animals. I. G. Priede and S. M. Swift, eds]. Ellis Horwood, Chichester, Sussex: 256-271. 